Chapter 5

\title{
Feasibility of Molecularly Targeted Therapy for Tooth Regeneration
}

\author{
Katsu Takahashi, Honoka Kiso, Kazuyuki Saito, \\ Yumiko Togo, Hiroko Tsukamoto, Boyen Huang and \\ Kazuhisa Bessho
}

Additional information is available at the end of the chapter

http://dx.doi.org/10.5772/58904

\section{Introduction}

The tooth is a complex organ that consists of enamel, dentin, cementum, and pulp. Missing teeth is frequently occurring problem in aging populations. To treat these defects, the current approach involves prostheses, autotransplantation, and dental implants. The exploration of new strategies for tooth replacement has become a hot topic. Using the foundations of experimental embryology, developmental and molecular biology, tooth regeneration is becoming realistic possibility. Several different methods have been proposed to achieve biological tooth replacement. These include scaffold-based tooth regeneration, cell pellet engineering, stimulation of the formation of a third dentition, and gene-manipulated tooth regeneration. The idea that a third dentition might be locally induced to replace missing teeth is an attractive concept (Young et al., 2005; Edward \& Mason, 2006; Takahashi et al., 2008, 2013). This approach is generally presented in terms of adding molecules to induce de novo tooth initiation in the mouth. Tooth development is the result of reciprocal and reiterative signaling between oral ectoderm-derived dental epithelium and cranial neural crest cellderived dental mesenchyme under genetic control (Thesleff, 2006). More than 200 genes are known to be expressed during tooth development (http://bite-it.helsinki.fi/). A number of mouse mutants are now starting to provide some insights into the mechanisms of supernumerary tooth formation. Multiple supernumerary teeth may have genetic components in their etiology and partially represent the third dentition in humans. Such candidate molecules might be those that are involved in embryonic tooth induction, in successional tooth formation, or in the control of the number of teeth. This means that it may be possible to induce de novo tooth formation by the in situ repression or activation of a single candidate molecule. In this review, 
we provide an overview of the collective knowledge of tooth regeneration, especially regarding the control of the number of teeth for molecularly targeted therapy by the stimulation of a third dentition.

\section{The third dentition}

It has been suggested that, in humans, a "third dentition" with one or more supernumerary teeth can occur in addition to the permanent dentition, and supernumerary teeth are sometimes thought to represent a partial post-permanent dentition (Ooe, 1969). The deciduous teeth are, ontogenetically, the first generation of teeth. The permanent teeth (except molar) belong to the second dentition. The term "third dentition" refers to the opinion that one more set of teeth can occur in addition to the permanent teeth (Figure 1). Human teeth are diphyodont excepting the permanent molars. The normal mouse dentition is monophyodont and composed of one incisor and three molars in each quadrant. The number of teeth is usually strictly determined. It was initially reported that there is an anlagen of the third dentition in some mammals (Leche, 1893). The presence of an epithelial anlagen of the third dentition was also noticed in humans (Ooe, 1969). The teeth and anlagen that appear in third dentition in serial sections of infant jaws and some fetuses have been analysed. The epithelium which is considered as the anlagen of the third dentition develops lingual to all permanent tooth germs (Ooe, 1969). Furthermore, when it appears, the predecessor (permanent tooth germ) is in the bellshaped stage (Ooe, 1969). The timing of appearance of the third dentition seems to be after birth (Table 1). This means that we have a chance to access the formation of the third dentition in the mouth.

Detailed histological analysis of the tooth replacement in these models indicates that the successional teeth are initiated from the dental lamina epithelium, which grows from the lingual side of the deciduous tooth enamel organ, and it later elongates and buds into the jaw mesenchyme, forming successional teeth. Jarvien et al. showed that, in the ferret, Usag-1(also known as Sostdc1, Ectodin, and Wise) is expressed in the elongating successional dental lamina at the interface between the lamina and deciduous tooth, as well as the buccal side of the dental lamina, suggesting that Sostdc1 plays a role in defining the identity of the dental lamina(Jarvinen et al., 2009). Handrigan et al. analysed successional tooth formation in the snake and in lizard, and proposed that dental epithelium stem cells are responsible for the formation of successional lamina, and Wnt signaling may regulate the dental eithelial stem cell fate in these cells (Handrigan et al., 2010). Maintenance or reactivation of component dental lamina is thus pivotal for the replacement tooth and supernumerary formation.

\section{Human syndromes associated with supernumerary teeth}

Supernumerary teeth can be associated with a syndrome or they can be found in nonsyndromic patients. Only $1 \%$ of non-syndromic cases have multiple supernumerary teeth, 
which occur most frequently in the mandibular premolar area, followed by the molar and anterior regions, respectively (Yusof, 1990; Yague-Garcia et al., 2009). Genetic mutations have been associated with the presence or absence of individual types of teeth.

Supernumerary teeth are associated with 8 syndromes and developmental abnormalities in which the resposible genes already have been isolated (Takahashi et al., 2013). The percentage occurrence in CCD is $22 \%$ in the maxillary incisor region and $5 \%$ in the molar region (Shafer, 1983). CCD is a dominantly inherited skeletal dysplasia caused by mutations in RUNX2 (Mundlos et al., 1997). There is a wide spectrum of phenotypic variability ranging from the full-blown phenotype to an isolated dental phenotype characterized by supernumerary tooth formation and/or the delayed eruption of permanent teeth in CCD (Takahashi et al., 2008). Runx2-deficient mice were found to exhibit lingual buds in front of the upper molars, and these were much more prominent than in wild-type mice (Aberg et al., 2004). These buds presumably represent the mouse secondary dentition, and it is likely that RUNX2 acts to prevent the formation of these buds. Runx2 regulates the proliferation of cells and may exert specific control on the dental lamina and formation of successive dentitions. Runx2 heterozygous mutant mice mostly phenocopied the skeletal defects of CCD in humans, but with no supernumerary tooth formation (Otto et al., 1997). Notably, in Runx2 homozygous and heterozygous mouse upper molars, a prominent epithelial bud regularly presents. This epithelial bud protrudes lingually with active Shh signaling, and it may represent the extension of the dental lamina for successional tooth formation in mice. Hence, although Run $x 2$ is required for primary tooth development, it prevents the growth of the dental lamina and successional tooth formation (Otto et al., 1997).

Familial adenomatous polyposis (FAP), also named adenomatous polyposis of the colon (APC), is an autosomal dominant hereditary disorder characterized by the development of many precancerous colorectal adenomatous polyps. In addition to colorectal neoplasm, individuals can develop variable extracolonic lesions, including upper gastrointestinal polyposis, osteomas and dental anomalies (Wijn et al., 2007). Dental abnormalities include impacted teeth, congenital absence of one or more teeth, supernumerary teeth and odontomas (Wijn et al., 2007). Gardner syndrome is a variant of FAP characterized by multiple adenomas of the colon and rectum typical of FAP together with osteomas and soft tissue tumors (Chimenos-Kustner et al., 2005). Supernumerary teeth and osteomas were originally described as a part of Gardner syndrome, but they can also occur in FAP patients with or without other extracolonic lesions (Chimenos-Kustner et al., 2005; Wijn et al., 2007). FAP and Gardner syndrome are caused by a large number of germinal mutations in the Apc gene (Groden et al., 1991). Apc is a tumor suppressor gene involved in the down-regulation of free intracellular $B-$ catenin, the major signal transducer of the canonical Wnt signaling pathway (Groden et al., 1991). Approximately $11-27 \%$ of patients have supernumerary teeth, but, so far, no specific codon mutation of the $A p c$ gene has been found to correlate with supernumerary teeth.

The identification of mutations in RUNX2 causing an isolated dental phenotype in CCD and in $A p c$ causing FAP has attracted attention as a possible route towards inducing de novo tooth formation. 


\section{Supernumerary tooth formation in a mouse model}

A number of mouse mutants provide insights into the supernumerary tooth formation (Takahashi et al., 2013). Several mechanisms by which supernumerary tooth might arise in mice have been proposed (Murashima-Suginami et al., 2008; Wang et al., 2009). One plausible explanation for supernumerary tooth formation is the rescue of tooth rudiments such as within the diastema region or maxillary deciduous incisor (Yamamoto et al., 2005; MurashimaSuginami et al., 2007; Lagronova-Churava et al., 2013). During early stages of mouse tooth development transient vestigial tooth buds develop in the diastema area; developing to the bud stage yet later regressing and disappear by apoptosis, or merge with the mesial crown of the adjacent first molar tooth organ (Yamamoto et al., 2005; Lagronova-Churava et al., 2013). The rudimentary maxillary incisor regressed by apoptotic elimination of mesenchymal cells (Murashima-Suginami et al., 2007). We demonstrated that USAG-1-deficient mouse model has supernumerary incisors in the maxillary and mandible, a fused tooth in the maxillary and mandibular molar regions, and a supernumerary tooth was also located in front of the first mandibular molar (Figure 2). Increased BMP signaling results in supernumerary teeth in the Usag-1-deficient mouse model (Murashima-Suginami et al., 2008). Recently, we claimed that gene interactions between $B M P-7$ and USAG-1 regulate the supernumerary maxillary incisor formation (Kiso et al., 2014). BMP-7 was co-localized with USAG-1 in the area of the maxillary rudiment incisor tooth germ in addition to the regular maxillary incisor tooth organ. USAG-1 abrogation rescued the apoptotic elimination of mesenchymal cells in the rudimentary maxillary incisor tooth primordia at E15, whereas the tooth sizes were comparable (Murashima-Suginami et al., 2007, 2008). The apoptotic mesenchymal cells in USAG-1-/BMP-7-/are similar to USAG-1/+/BMP- $-7^{+/+}$in contrast to that of $U S A G-1^{-1 /} / B M P-7^{+/+}$. These results support our interpretation that USAG-1 functions as a novel BMP-7 antagonist in the maxilla. We confirmed that increased $B M P$ signaling in supernumerary teeth of the USAG-1 deficient mice could be prohibited by $B M P-7$ abrogation. In the contrast, to test whether BMP-7 has the potential to induce supernumerary tooth formation, we performed explant culture and subsequent subrenal kidney capsule culture. The incisor explants supplemented with BMP-7 in USAG-1+-as well as USAG-1-1-have supernumerary tooth in similar numbers after 20 days culture, while these cultured explants in USAG-1/+retained normal tooth number (Figure 2). These results demonstrated that $B M P-7$ can induce supernumerary tooth formation, however it is impossible to induce extra tooth by only BMP-7 (Kiso et al., 2014). While we showed that enhanced $B M P$ signaling resulted in supernumerary teeth, we also demonstarated that $B M P$ signaling was modulated by Wnt signaling in the Usag-1-deficient mouse model (Figure 3) (Murashima-Suginami et al., 2008). Canonical Wnt/ $\beta$-catenin signaling and its down-stream molecule Lef- 1 are essential for tooth development. Overexpression of Lef- 1 under the control of the K14 promoter in transgenic mice leads to the development abnormal invaginations of the dental epithelium in the mesenchyme and formation of a tooth-like structure (Zhou et al., 1995). De novo supernumerary teeth arising directly from the primary tooth germ or dental lamima have been reported in Apc loss-of-function or $\beta$-catenin gain-of-function mic. It was 
demonstrated that mouse tooth buds expressing stabilized $\beta$-catenin give rise to extra teeth (Jarvinen et al., 2006). Conditional knockout of the $A p c$-gene resulted in supernumerary teeth in mice (Wang et al., 2009). Notably, adult oral tissues, especially young adult tissues, are still responsive to the loss of Apc (Wang et al., 2009). In old adult mice, supernumerary teeth can be induced on both labial and lingual sides of the incisors, which contain adult stem cells supporting the continuous growth of mouse incisors (Huysseune et al., 2004). In young mice, supernumerary tooth germs were induced in multiple regions of the jaw in both incisor and molar regions. They can form directly from the oral epithelium, in the dental lamina connecting the developing molar or incisor tooth germ to the oral epithelium, in the crown region, as well as in the elongating and furcation area of the developing root (Wang et al., 2009). Wnt/BMP signaling seems to be essential in supernumerary tooth formation (Figure 3).

We also demonstrated that $C e b p b$ deficiency was related to the formation of supernumerary teeth(Figure 2). A total of $66.7 \%$ of $\mathrm{Cebpb}^{-/}-12$-month-olds sustained supernumerary teeth and/ or odontomas in the diastema between the incisor and the first molar (Huang et al., 2012). Furthermore, it was suggested that the dental epitheilal stem cells might be contributated to supernumerary tooth formation in mice (Figure 2).

These mouse models clearly demonstrated that it was possible to induce de novo tooth formation by the in situ inhibition or activation of single molecule such as USAG-1, BMP7 or CEBPB.

\section{Molecularly targeted therapy}

Molecularly targeted therapy is a type of treatment that uses drugs or other substances to identify and attack specific types of cells by interfering with specific targeted molecules.

Most targeted therapies are either small moleclule or monoclonal antibodies. Small molecules are typically able to diffuse into cells and can act on target that are found inside the cells. Monoclonal antibodies usually can not penetorate the surface membrane and are directed against targets that are outside cells or on the surface of cells. Candidates for small molecules are identified in screeing the effect of thousands of test compounds on a specific target. The best candidates are then chemically modified to produce many closely related versions. Monoclonal antibody are prepared first by immunized animals such as mice with purified target moleclules.They are humanized by replacing the animal portion of the antibody with human portion. More than 40 molecularly targeted cancer therapy have been approved by the U.S Food and Drug Administration for the treatment of specific type of cancer. Many more are in clinical trials or preclinical testing (Forscher et al., 2014). Recent molecularly targeted therapy also has successfully been introduced into the treatment of several inflammatory rheumatic diseases such as rheumatoid arthritis (Mocsai et al., 2014).

Molecularly targeted therapy provides a unique tool for the delivery of previously identified signaling molecules in both time and space that may significantly augment our progress 
toward clinical tooth regeneration. Stimulation of the formation of a third dentition comprises an attractive concept (Figure 4). This approach is generally presented in terms of adding molecules to induce de novo tooth initiation in the mouth. We have a chance to access the formation of the third dentition in the mouth, because the time of appearance of the third dentition seems to be after birth. Advances in our understanding of signal transduction by Wnt/BMP signalling in the supernumerary teeth formation offer numerous opportunities for devising new targeted therapies (Figure 3). This led to a new approach of drug development whereby targeted therapy are developed by directly targeting molecules thought to be involved in the the formation of a third dentition. A mojor approach for the development targeted therapeutics has been the application of monoclonal antibody for targeting molecules such as USAG-1.

Molecularly targeted therapy seems to be a suitable approach in tooth regeneration by stimulation of the third dentition.

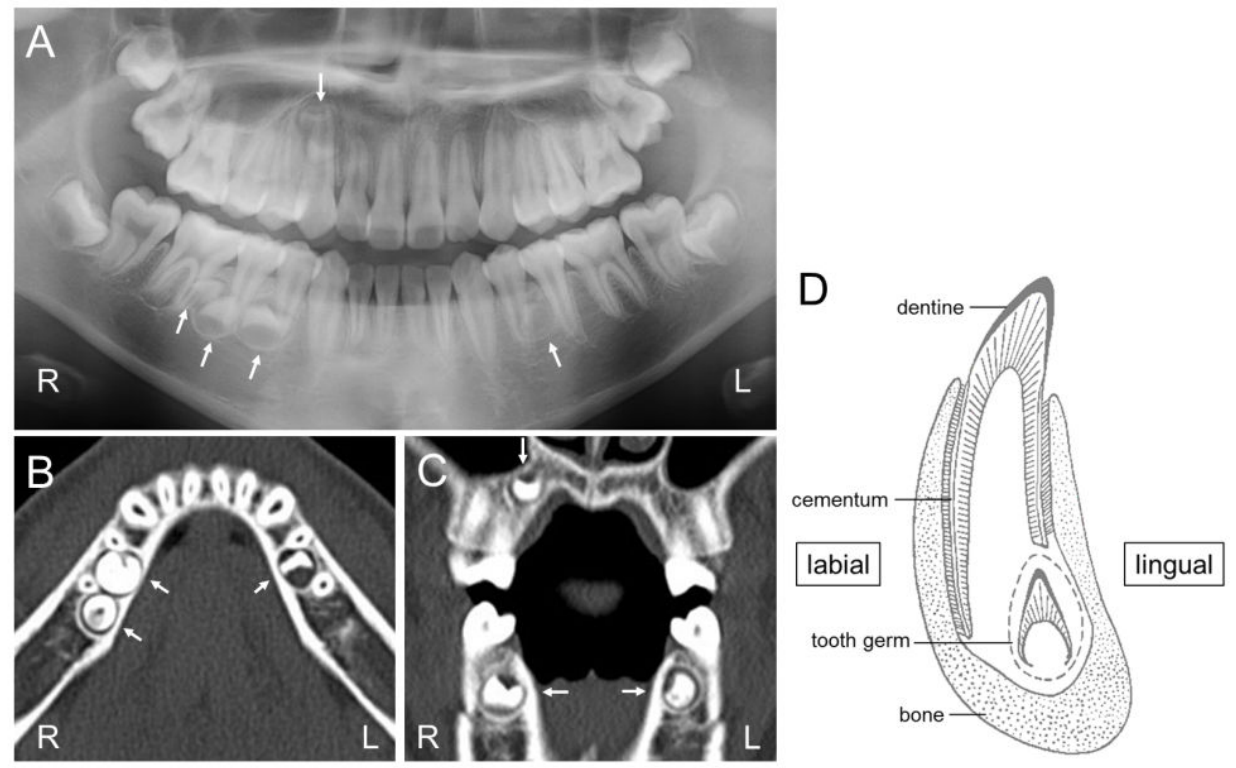

Figure 1. Multiple impacted supernumerary teeth (the third dentition) in a 13-year-old non-syndromic patient.

The third dentition develops lingual to the permanent tooth germ (D). All impacted supernumerary teeth in this patient are located to the lingual side of the permanent teeth (white arrow) (A-C). These multiple supernumerary teeth seem to be post-permanent dentition ("third dentition"). (Takahahsi et al., 2013, copy right, In Tech) 


\begin{tabular}{l|l|l}
\hline \multirow{2}{*}{ Teeth } & \multicolumn{2}{|l}{ The time of appearance of the third dentition } \\
\cline { 2 - 3 } & Maxilla & Mandible \\
\hline central incisors & $\sim 3$ months after birth & $2 \sim 3$ months after birth \\
lateral incisors & $8 \sim 9$ months after birth & $2 \sim 3$ months after birth \\
canines & $2 \sim 7$ months after birth & $2 \sim 3$ months after birth \\
the first premolar & 1 year 1 month $\sim 5$ years 4 months after birth & 1 year 1 month $\sim 5$ years 4 months after birth \\
the second premolar & 1 year 1 month $\sim 5$ years 4 months after birth & 2 years $\sim 5$ years 4 months after birth
\end{tabular}

Table 1. Timing of appearance of the third dentition (Takahahsi et al., 2013, copy right, In Tech)

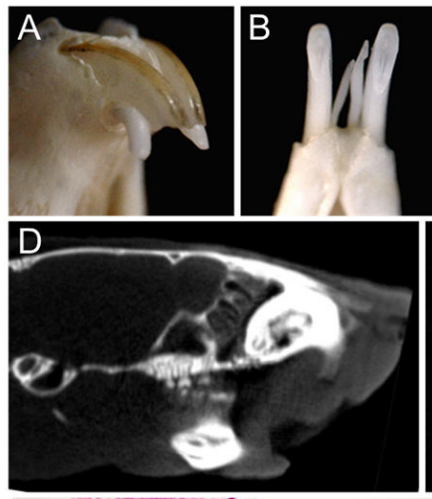

G

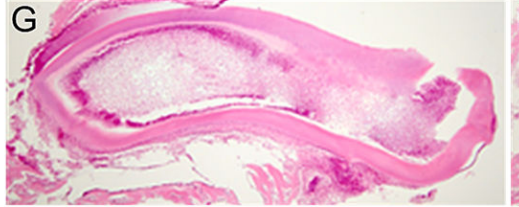

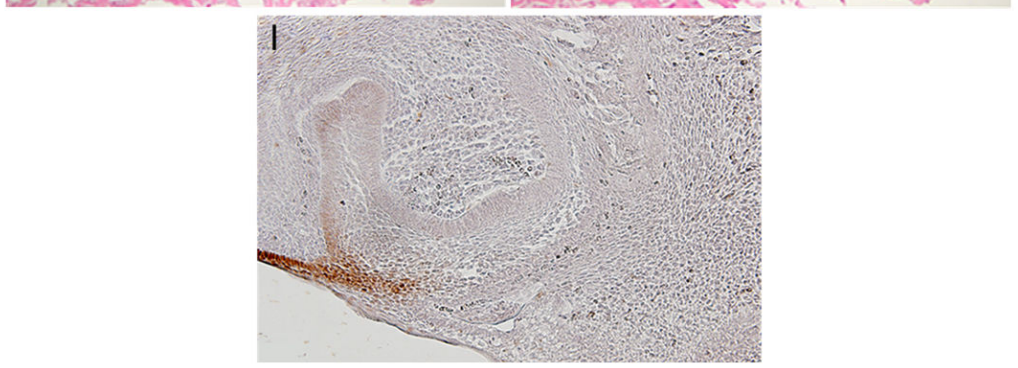
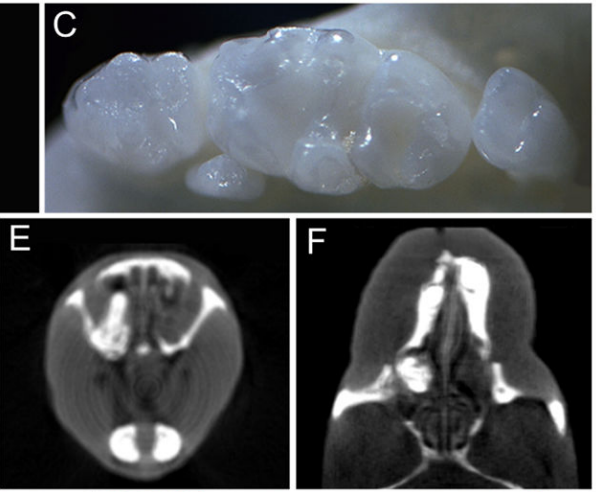

wastons -

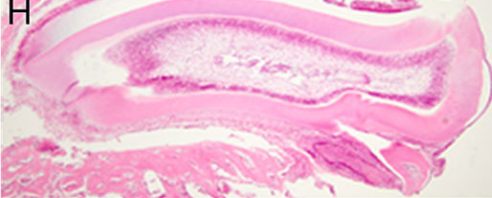

Figure 2. Supernumerary teeth formation in mouse model 
Usag-1 deficient mice (A-C) A: Oblique view of the maxillary incisors. B: Occlusal view of the mandibular incisors. C: Occlusal view of the mandibular molars. Micro-CT images of Cebpb dificient mice (D-F) A frontal view (D), a sagittal view (E) and a horizontal view (F) BMP-7 has potential to partially induce the formation of maxillary supernumerary incisors formation in vitro. The incisor explants supplemented with $(\mathrm{H}) /$ without $(\mathrm{G}) B M P-7$ in $U S A G-1^{+-}(\mathrm{G}, \mathrm{H})$ sagittal sections of explant. (I) Sox2 positive detal epithelial stem cells in sagittal sections of the rudimentary maxillary incisor tooth primordia at E15.

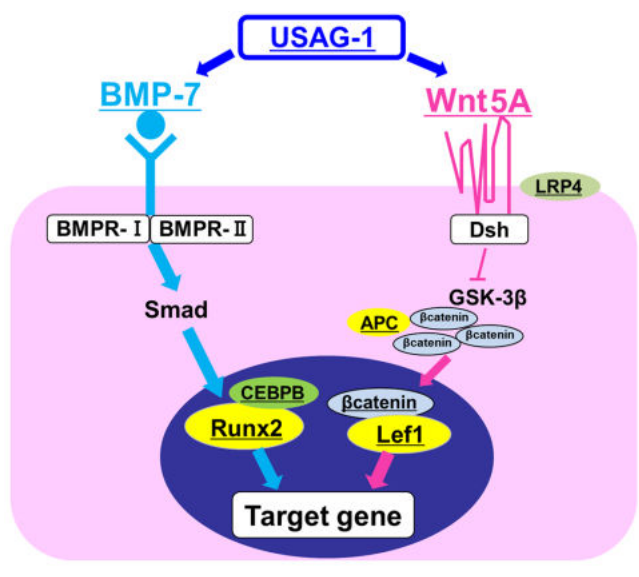

Figure 3. Wnt/BMP signaling in supernumerary tooth formation.

Underlined molecules are responsible genes for human syndromes or mutant mouse associated with supernumerary teeth

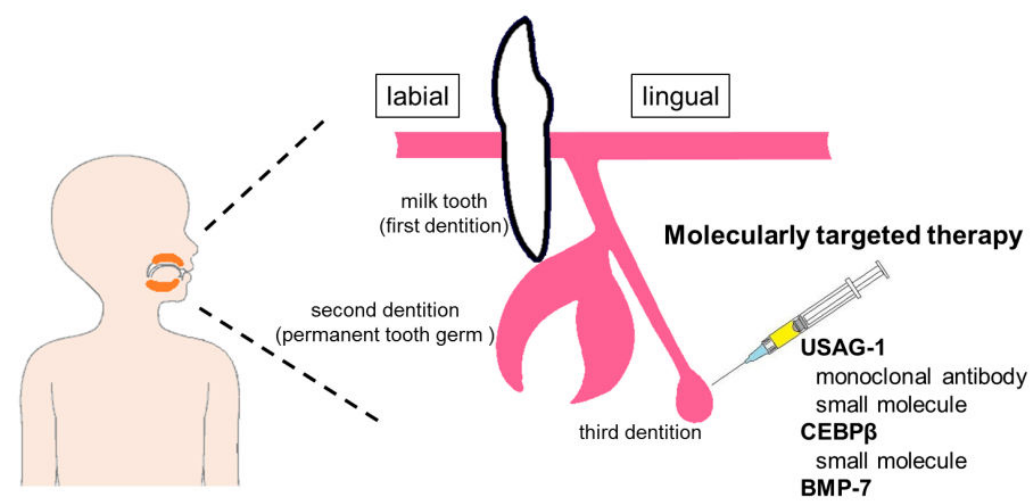

Figure 4. Molecularly targeted therapy for the tooth regeneration by stimulation of a third dentition 


\section{Conclusion}

We have a chance to access the formation of the third dentition in the mouth, because the timing of the appearance of the third dentition seems to be after birth. The identification of mutations in RUNX2 causing an isolated dental phenotype in CCD and supernumerary tooth formation in the mouse model clearly demonstrated that it was possible to induce de novo tooth formation by the in situ inhibition or activation of a single candidate molecule. These results support the idea that the de novo inhbition or activation of candidate molecules such as RUNX2 or USAG-1 might be used to stimulate the third dentition in order to induce new tooth formation in the mouse (Figure 4). Molecularly targeted therapy seems to be a suitable approach in tooth regeneration by stimulation of the third dentition.

\section{Acknowledgements}

This work was supported by Grant-in-Aid for Scientific Research(C):22592213 and 25463081 and A-STEP (Adaptable \& Seamless Technology Transfer Program through Target-driven R\&D) FS stage: AS231Z01061G and AS242Z02645Q.

\section{Author details}

Katsu Takahashi ${ }^{1}$, Honoka Kiso ${ }^{1}$, Kazuyuki Saito ${ }^{1}$, Yumiko Togo ${ }^{1}$, Hiroko Tsukamoto ${ }^{1}$ Boyen Huang ${ }^{2}$ and Kazuhisa Bessho ${ }^{1}$

1 Department of Oral and Maxillofacial Surgery, Graduate School of Medicine, Kyoto University, Japan

2 Department of Paediatric Dentistry, School of Medicine and Dentistry, James Cook University, Cairns, Australia

\section{References}

[1] Aberg T, Cavender A, Gaikwad JS, Bronckers AL, Wang X, Waltimo-Sirén J, Thesleff I, D'Souza RN. Phenotypic changes in dentition of Runx2 homozygote-null mutant mice. J Histochem Cytochem 2004;52(1):131-139.

[2] Chimenos-Küstner E, Pascual M, Blanco I, Finestres F. Hereditary familial polyposis and Gardner's syndrome: contribution of the odonto-stomatology examination in its diagnosis and a case description. Med Oral Patol Oral Cir Bucal 2005;10(5):402-409. 
[3] Edwards PC, Mason JM. Gene-enhanced tissue engineering for dental hard tissue regeneration: (1) overview and practical considerations. Head Face Med 2006;2:12.

[4] Forscher C, Mita M, Figlin R. Targeted therapy for sarcomas. Biologics. 2014;8:91-105.

[5] Groden J, Thliveris A, Samowitz W, Carlson M, Gelbert L, Albertsen H, Joslyn G, Stevens J, Spirio L, Robertson M, et al. Identification and characterization of the familial adenomatous polyposis coli gene. Cell 1991;66(3):589-600.

[6] Handrigan GR, Leung KJ, Richman JM. Identification of putative dental epithelial stem cells in a lizard with life-long tooth replacement. Development 2010;137(21): 3545-3549.

[7] Huang B, Takahashi K, Sakata-Goto T, Kiso H, Togo Y, Saito K, Tsukamoto H, Sugai M, Akira A, Shimizu A, Bessho K. Phenotypes of CEBPB Deficiency: Supernumerary Teeth and Elongated Coronoid Process. Oral Dis 2012; 19, 144-150, 2013

[8] Huysseune A, Thesleff I. Continuous tooth replacement: the possible involvement of epithelial stem cells. Bioessays 2004;26(6):665-671.

[9] Järvinen E, Salazar-Ciudad I, Birchmeier W, Taketo MM, Jernvall J, Thesleff I. Continuous tooth generation in mouse is induced by activated epithelial Wnt/beta-catenin signaling. Proc Natl Acad Sci U S A 2006;103(49):18627-18632.

[10] Järvinen E, Tummers M, Thesleff I. The role of the dental lamina in mammalian tooth replacement. J Exp Zool B Mol Dev Evol 2009 ;312B(4):281-291.

[11] Kiso, H., Takahashi, K., Saito, K., Togo, Y., Tsukamoto, H., Huang, B., Sugai, M., Shimizu, A., Tabata, Y., Economides, AN., Slavkin, HC., Bessho, K. Interactions between BMP-7 and USAG-1 (uterine sensitization-associated gene-1) regulate supernumerary organ formations. PLoS ONE. 2014, 9, e96938, 2014

[12] Kratochwil K, Dull M, Farinas I, Galceran J, Grosschedl R. Lef1 expression is activated by BMP-4 and regulates inductive tissue interactions in tooth and hair development. Genes Dev 1996;10(11):1382-1394.

[13] Leche W. Studien uber die Entwicklung des Zahnsstemsbei den Saugetieren. Morph Jb 1893;19: 502-574.

[14] Mócsai A, Kovács L, Gergely P. What is the future of targeted therapy in rheumatology: biologics or small molecules? BMC Med. 2014;12:43.

[15] Mundlos S, Otto F, Mundlos C, Mulliken JB, Aylsworth AS, Albright S, Lindhout D, Cole WG, Henn W, Knoll JH, Owen MJ, Mertelsmann R, Zabel BU, Olsen BR. Mutations involving the transcription factor CBFA1 cause cleidocranial dysplasia. Cell 1997; 89(5): 773-779.

[16] Murashima-Suginami A, Takahashi K, Kawabata T, Sakata T, Tsukamoto H, Sugai M, Yanagita M, Shimizu A, Sakurai T, Slavkin HC, Bessho K. Rudiment incisors sur- 
vive and erupt as supernumerary teeth as a result of USAG-1 abrogation. Biochem. Biophys. Res. Commun 2007;359(3):549-555.

[17] Murashima-Suginami A, Takahashi K, Sakata T, Tsukamoto H, Sugai M, Yanagita M, Shimizu A, Sakurai T, Slavkin HC, Bessho K. Enhanced BMP signaling results in supernumerary tooth formation in USAG-1 deficient mouse. Biochem Biophys Res Commun 2008;369(4):1012-1016.

[18] Ooë T. Epithelial anlagen of human third dentition and their migrations in the mandible and maxilla. Okajimas Fol Anat Jap 1969; 46(5):243-251.

[19] Otto F, Thornell AP, Crompton T, Denzel A, Gilmour KC, Rosewell IR, Stamp GW, Beddington RS, Mundlos S, Olsen BR, Selby PB, Owen MJ. Cbfa1, a candidate gene for cleidocranial dysplasia syndrome, is essential for osteoblast differentiation and bone development. Cell 1997;89(5):765-771.

[20] Shafer, W. G., Hine, M. K., and Levi, B. M. Textbook of oral pathology $4^{\text {th }}$ Ed. Philadelphia:WB Saunders Co;1983.

[21] Takahashi, K., Sakata, T., Murashima-Suginami, A., Tsukamoto, H., Kiso, H. and Bessho, K. Tooth regeneration: Potential for stimulation of the formation of a third dentition by one gene. Current Topics in Genetics 2008;3: 77-82.

[22] Takahashi, K., Kiso, H., Saito, K., Togo, Y., Tsukamoto, H., Huang, B. and Bessho, K. (2013) Feasibility of gene therapy for tooth regeneration by stimulation of a third dentition: Gene Therapy-Tools and Potential Applications, In Tech, Rijeka, Croatia, $30,727-744$

[23] Thesleff I. The genetic basis of tooth development and dental defects. Am J Med Genet A 2006;140(23):2530-2535.

[24] Wang XP, O'Connell DJ, Lund JJ, Saadi I, Kuraguchi M, Turbe-Doan A, Cavallesco R, Kim H, Park PJ, Harada H, Kucherlapati R, Maas RL. Apc inhibition of Wnt signaling regulates supernumerary tooth formation during embryogenesis and throughout adulthood. Development 2009;136(11):1939-1949.

[25] Wijn MA, Keller JJ, Giardiello FM, Brand HS. Oral and maxillofacial manifestations of familial adenomatous polyposis. Oral Dis 2007;13(4):360-365.

[26] Yagüe-García J, Berini-Aytés L, Gay-Escoda C. Multiple supernumerary teeth not associated with complex syndromes: a retrospective study. Med Oral Patol Oral Cir Bucal 2009;14(7):E331-336

[27] Yamamoto H, Cho SW, Song SJ, Hwang HJ, Lee MJ, et al. (2005) Characteristic tissue interaction of the diastema region in mice. Archives of oral biology 50: 189-198.

[28] Young CS, Abukawa H, Asrican R, Ravens M, Troulis MJ, Kaban LB, Vacanti JP, Yelick PC. Tissue-engineered hybrid tooth and bone. Tissue Eng 2005;11(9-10): 1599-1610. 
66 New Trends in Tissue Engineering and Regenerative Medicine - Official Book of the Japanese Society for Regenerative Medicine

[29] Yusof WZ. Non-syndrome multiple supernumerary teeth: literature review. J Can Dent Assoc 1990;56(2):147-149.

[30] Zhou P, Byrne C, Jacobs J, Fuchs E. Lymphoid enhancer factor 1 directs hair follicle patterning and epithelial cell fate. Genes Dev1995;9(6):700-713. 